\title{
TECHNOLOGY FOR SUSTAINABLE DEVELOPMENT
}

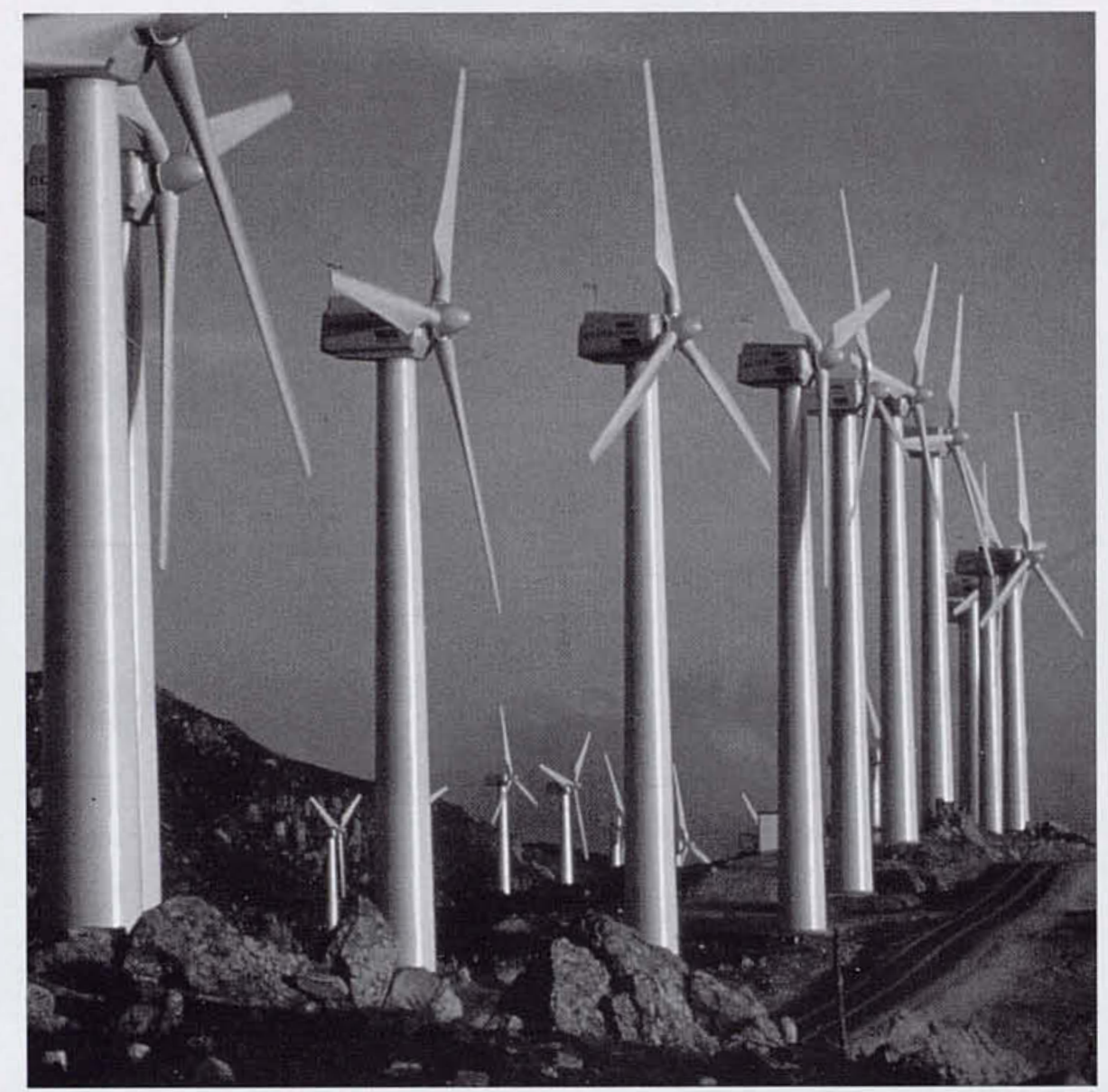

WIND PARK AT TARIFA

MORE AND MORE PEOPLE AGREE ON THE NEED TO INVEST EFFORTS AND RESOURCES IN A CLEANER, MORE ENVIRONMENT-CONSCIOUS FUTURE, BUT WITHOUT RENOUNCING THE ADVANTAGES OF SCIENCE AND TECHNOLOGY. IN THE ENERGY SECTOR, ECOTĖCNIA HAS BEEN A PIONEER IN THIS APPROACH. THIS HAS RESULTED IN SEVERAL TECHNOLOGICAL SOIUTIONS WHICH HAVE SHOWN THEMSELVES TO BE PROFITABLE AND, SUBSEQUENTLY, THAT SUSTAINABLE DEVELOPMENT IS NO UTOPIA. 

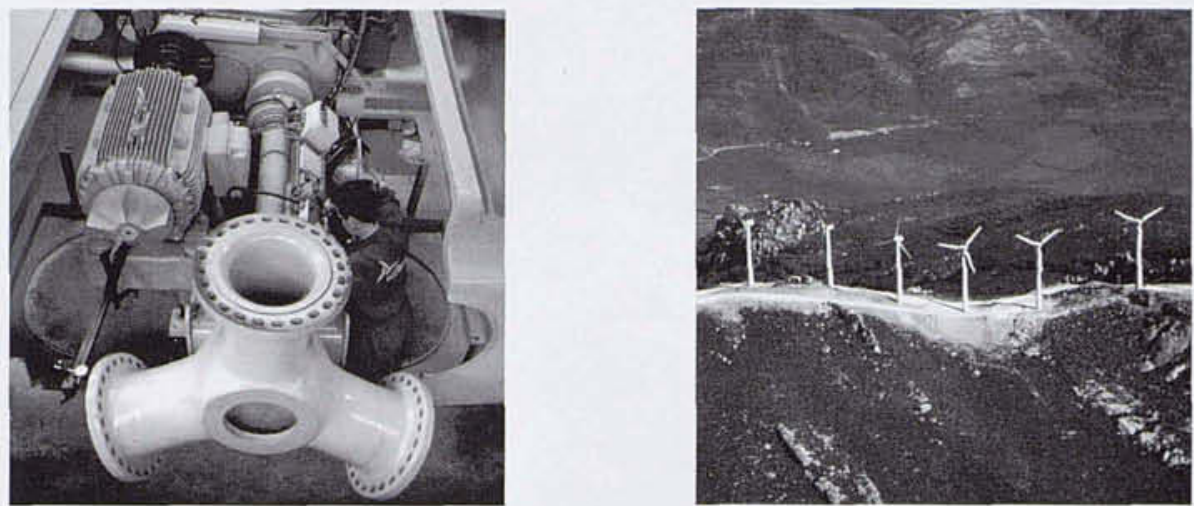

ASSEMBIY WORKSHOP

$\mathbf{T}$ he $30,830 \mathrm{MWh}$ produced by the 50 Ecotècnia 20/150 Wind turbines $(20$ metres being the diameter of the circle formed by the three revolving blades and 150 the nominal power in $\mathrm{kW}$ ) at the wind farm in Tarifa (Andalusia) over a year of operations are the most obvious proof that wind energy today is within reach of any society wanting to make swift progress along the path of ecologically sustainable energy sources.

To reach this landmark, the Catalan cooperative Ecotècnia has had to work hard and for a long time. It was set up in 1981 in Barcelona by eight people, most of whom had had advanced technical training, while only a few had any previous professional experience. The capital put forward by the founder members was very small and the firm gradually increased it with contributions from members in the monetary equivalent of the hours worked.

Its formation was, we might say, forced by the fact that the CDTI (Centre for Technological and Industrial Development) had announced a competition for the design and construction of $15 \mathrm{~kW}$ prototype wind turbines. Being one of the three winners of the competition was a dream come true for a group of people who since the middle of the seventies had been concerned about clean and renewable energy sources and had been reading up on the subject, in particular wind power.

Early in March 1984, on a peak of the hills separating the Alt Empordà from the Baix Empordà (Valldevià, Vilopriu) and with a large attendant public, the first wind turbine connected to the $\mathrm{Ca}$ talan electrical grid was inaugurated. This first trial was a genuine technological test-bed for the fine tuning of the different elements making up a wind energy converter system.

The success of that initial experience encouraged the members of the cooperative, who, on the basis of this prototype, went on to design a series of commercial wind turbines, first with a 25 $\mathrm{kW}$ yield and then with a $30 \mathrm{~kW}$ yield, and with blades six metres long. These machines were a basic part of the Renewable Energies Plan introduced by the Spanish Ministry of Industry and Energy (1986-1988), especially after the success of the experimental wind farm in Granadilla (Tenerife, Canary Islands). Of the four wind farms foreseen in the plan, two were equipped entirely with Ecotècnia 12/30 wind turbines: Ontalafia (La Mancha) and Tarifa (Andalusia).

The favourable results obtained at these first wind farms led Ecotècnia to design bigger and more powerful wind turbines. This was possible through the co-operative's participation in the technological development programmes of the DGXVII of the Commission of the European Communities and the support of the Spanish government's IADE IInstitute for Energy Diversification and Economy). The result was a $150 \mathrm{~kW}$ wind turbine with 10-metre blades. The prototype was installed at Tarifa in the summer of 1989. Though only a prototype, this wind turbine was considered the "best wind turbine of 1991" by the Fraunhofer Institute for Solar Energy Systems, which analyses the performance of more than 4,000 wind turbines installed all over Europe, on account of its having produced $1,554 \mathrm{Wh}$ per square metre swept by the blades per year. The same wind turbine ranked fifth in 1990. Up until the end of 1993 it had produced 1,997 MWh, with a capacity factor exceeding $30 \%$, having reached $37 \%$ in 1991.

On the basis of this successful experience, Ecotècnia helped to set up Energía Eólico del Estrecho, a company promoting a $10 \mathrm{MW}$ wind farm lof which 7.5 MW come from 50 20/150 wind turbines). This wind farm started producing electricity at the end of 1992.

Today, Ecotècnia has a 200 kW prototype with 12-metre blades in operation at Tarifa and is working on the design of a $500 \mathrm{~kW}$ wind turbine and on a wind farm planned for the Baix Ebre region (Catalonia), on the Serra del Boix in Tortosa. This wind farm will consist of $27150 \mathrm{~kW}$ wind turbines and production is expected to be of the order of 8,000 MWh per year. The project is being developed by PEBESA (Parc Eòlic del Baix Ebre, SA), a consortium made up of the Baix Ebre Regional Council, Tortosa Town Hall, the Catalan Energy Institute (ICAEN), the IDAE and Ecotècnia itself. Work is expected to start in mid-1994. 